\title{
Intercultural Competence for Teachers of German as a Foreign Language - Mixed Game Model and Multi-Collectivity
}

\author{
Marion Grein \\ German Department \\ Johannes Gutenberg-University of Mainz \\ Germany
}

\begin{abstract}
Every language teacher is in need of intercultural competence. In Germany, the terms "culture" and "intercultural" are under attack and, thus, the necessity of intercultural trainings is often negated. In my article, I will combine two approaches concerned with cultural differences, the so called Dialogic Action Game (Mixed Game Model; MGM) and the approach of Multi-Collectivity. The linking of these two approaches will focus shared values on the one hand and diversity on the other. Applying both approaches in teaching intercultural competence transcends the dissenting opinions of the impact of culture.
\end{abstract}

Keywords: German as a Foreign Language; Intercultural Competence; Minimal Action Game; Mixed Game Model; Dialogue Studies; Multi-Collectivism; Language Teachers

\section{Introduction}

In the age of globalisation, intercultural competence, understood as a basic skill, is essential for every human being; but especially German as a Foreign (GaFL) and German as a Second Language (GaSL) teachers who deal with culturally heterogeneous course participants on a daily basis can only make their lessons successful if they are - besides enjoying their work - inter-culturally competent. I would like to elucidate that negating cultural differences is of little help. In my opinion, since the $1990 \mathrm{~s}$, the term 'intercultural' has been wrongly criticised repeatedly to the effect that 'inter' implies that there are two clearly distinguishable cultures and that this view would amplify differences between cultures (cf. Welsch 1994). Instead, the term 'trans'cultural has been introduced which in its strongest form negates culture-specific differences. The interpretation of transcultural according to Vanderheiden \& Mayer (2014: 31), which formulates that 'transcultural' starts from a constructivist understanding of culture and that the crossing of constructed socio-cultural boundaries seems reasonable. In my opinion, this is merely a question of semantics and an absolute negation of culture-specific differences seems pointless. In this article, I would like to combine two concepts that I believe are fundamental for the training of the necessary 'intercultural' competence for GaFL/GaSL teachers: The Mixed Game Model (MGM) and the approach of Multi-Collectivity. In the 2.chapter, 'Intercultural Competence' and its training at the University of Mainz is briefly discussed. In the 3rd chapter, the Mixed Game Model according to Weigand (2010) and the Multi-Collectivity model according to Rathje (2014) are drafted and connected. A short summary follows.

\section{Intercultural Competence}

In the 1980s, attempts were made to make intercultural competence tangible with exhaustive lists. Intercultural competence was subdivided into additive sub-competences, such as 'empathy', 'tolerance for ambiguity', 'selforiented role behaviour' (cf. Ruben 1975), 'cultural awareness' (cf. Triandis 1977), 'open-mindedness', respect for cultural differences' or also 'interaction attentiveness' (cf. Chen \& Starosta 1997) and 'adaptability' (cf. Fritz, Möllenberg\& Chen 2004). Without negating or abandoning these partial competences, so-called structural models came to the fore in the 1990s (cf. Gersten 1990; Zülch 2004: 22ff.). They divide intercultural competence into cognitive (e.g. 'I know that personal distance is culture-specific, i.e. Uzbeks stand closer to one another'), affective ('I know how it feels when my personal distance behaviour is exceeded') and behavioural ('I can adapt to the distance behaviour of the "foreign" culture') sub-constructs. Müller \& Gelbrich (2004) developed a structural model that supplements intercultural competence with 'effectiveness' and 'appropriateness'.

Intercultural competence is thus 'the ability to interact effectively and appropriately with members of other cultures’ (Müller \& Gelbrich 2004: 793; see also Bergemann \& Bergemann 2005: 62). 


\begin{tabular}{ll}
\hline affective & effectiveness \\
\hline $\begin{array}{l}\text { low ethnocentrism } \\
\text { impartiality }\end{array}$ & $\begin{array}{l}\text { social adaptability } \\
\text { professional adaptability } \\
\text { openness }\end{array}$ \\
empathy & \\
\hline cognitive & appral contentment \\
\hline cultural awareness & knowing the cultural rules of the host country \\
self-awareness & recognition of the feelings of the 'others' \\
cultural knowledge & realistic expectations \\
\hline $\begin{array}{l}\text { related to behaviour } \\
\text { respect }\end{array}$ & \\
\hline $\begin{array}{l}\text { flexibility } \\
\text { communication skills } \\
\text { tolerance of ambiguity }\end{array}$ & \\
\hline
\end{tabular}

Table 1: Sub-constructs of Intercultural Competence (based on Müller \& Gelbrich 2004: 793)

As these areas can neither be clearly defined nor mediated separately from each other (cf. Bolten 2006: 86), process-oriented models are now in the limelight. Intercultural competence, here, is understood as the competence to act, which continues to take into account the tripartite division into cognitive, affective and behavioural. The basic precondition for the acquisition of intercultural competence is an awareness of the ethnocentrism of every human being, i.e. the knowledge that the foreign is always assessed on the basis of one's nativesystem of values. Process models therefore see intercultural competence as a holistic interplay of individual, social, professional and strategic actions in intercultural contexts, i.e. that personal and social competences are prerequisites to being successful in 'cultural contact'. However, this requires general knowledge of the areas in which cultures can differ. At the same time, the individuality of each person must not be ignored, nor must differences be combined with judgement (good - bad). Bolten (2006: 86) states: 'Intercultural competence is the ability to relate individual, social, professional and strategic sub-competences in their best possible combination to intercultural contexts of action.'

Overall, the acquisition of intercultural competence is a lifelong process and not all sub-constructs can be taught. However, the precondition is the sensitization for culture-specific differences, such as with the help of Hall's (1966: Proxemics, 1976: high vs. low context, 1983: monochronic vs. polychronic) or Hofstadter's (2017: power distance; individualism vs. collectivism, masculinity vs. femininity; uncertainty avoidance, long-term vs. shortterm orientation, enjoyment vs. restraint) dimensions. People who deny any culture-specific differences have likely had insufficient experiences with people from other cultures. The seminars for the promotion of intercultural competence in the Master's programme GaFL / GaSL at the University of Mainz have the following content, of which the approach of dialogue research and Multi-Collectivity are further explained in the following chapters.

o Cultural definitions (historical)

- Communication models with a focus on the Dialogical Action Game / Mixed Game Model (MGM)

○ Multi-Collectivity approach

o Cultural differences (dimensions)

○ Stereotypes \& prejudices

Definition of learning objectives:

Graduates are able to recognise and reflect on culturally determined differences in perception, thinking, feeling, judgement and action within themselves and others. They are aware of their own cultural imprint, know that stereotypes are necessary to classify the world, but are changeable. They can productively deal with cultural differences, foreignness and otherness on a cognitive, emotional and ideally also practical level. With the help of many interactive methods, the differences should also be 'felt'. In order to achieve this learning objective, the Dialogical Action Game and Multi-Collectivity approach, which are outlined below, are used. 


\section{The Mixed Game Model and Multi-Collectivity}

In the following, I would like to combine the two models and argue why an entry into the field of inter-culturality through the fusion of models makes the fundamental negation of cultural differences unnecessary. In doing so, it seems sensible to first sketch out the Mixed Game Model and subsequently the approach of Multi-Collectivity, in order to then link them together.

\subsection{The Mixed Game Model (MGM)}

As explained in Grein (2017a, 2017b, 2018), the use of language can only be analysed in a holistic framework that integrates human skills such as cognition, perception, emotions, rational behaviour and cultural factors (cf. also Damasio 2000). Language use cannot be limited to 'linguistic rules'. People use communicative techniques that can be derived from existing linguistic means and principles. There is no object 'language' as such in performance; there is only the human ability of speaking which however cannot be separated from other abilities: speaking is integrated with thinking and perceiving. (Weigand 2010: 2)

From a dialogical perspective, it is not the speaking person who faces the world (as in conventional monologically oriented speech act theory), but another speaking person within the world (cf. Weigand 2009a: 79).

Basic requirements for a language analysis according to Weigand (2009a: 271) are the following premises:

1. Language is spoken by people and thus cannot be analysed separately from them.

2. People act according to needs and interests. Interest is the key concept to explain human action.

3. People differ from each other, they cannot only be divided into speaker and listener.

4. Humans are social beings. They use language to understand each other (communication and understanding). They negotiate their positions, plans and interests.

5. Language accepts misunderstandings and misapprehensions.

6. For people, there is no independent world, there is no reality as such, but only a world as it is perceived by people.

7. The smallest autonomous communicative unit is the Action Game (interdependence of proactive and reactive speech act), a unit of our culturally shaped world, which consists of different communicative worlds of the respective speakers.

8. The Action Game is not to be seen as a type of a specific situation, but is determined by the interactive goals and interests.

9. The authentic text is a component of the Action Game. People use different abilities as communicative means. They use verbal texts while at the same time inferring and relying on how they perceive the linguistic situation. Language can thus never be entirely described from the outside perspective, i.e. the viewer. Linguistic corpora can therefore never be flawlessly interpreted and understood.

10. Not everything is expressed explicitly, and not everything can be explicitly voiced due to the complexity of meanings.

According to Weigand (2010: 4), the primary interest of language analysis is to describe and explain how people as cultural beings - master human coexistence. Linguistic rules must be replaced by principles of probability. The basic principles here are the Action Principle (AP) and the Dialogic Principle (DP). The Principle of Action is that we communicate because we have a specific communicative interest. In order to realise this communicative interest (and this can also merely be to maintain social relationships), we use various communicative or dialogical means (e.g. verbal, cognitive and perceptive means). Each communicative function can be realised by a larger number of concrete expressions or statements (e.g. request to open the window: Can you open the window, open the window, please; it's stuffy here; a bit of fresh air would be good, open the window! etc., etc.). The different but functionally equivalent statements depend, among other things, on the respective situation. Different goals require specific linguistic means. In addition to the situation (which can also be perceived differently), the personality and the emotions associated with the situation also play a role. People have divergent assessments and evaluations of the same situation.

The dialogic relation is not only a situational one. Our communicative means of language, perception and cognition cannot be considered separately. There are on the one hand innate and on the other hand differences acquired due to different experiences between the interactants. Every human being brings their own cognitive horizons, preferences and emotions. (Weigand 2009a: 147) 
The Dialogical Principle (DP) fundamentally assumes that communicative actions are dialogical actions, i.e. - as already explained - that the initiative and the reactive speech act form a fixed unit that is equally understood as the smallest communicative unit. The communicative goal of every Action Game (or dialogue) is to achieve a common understanding and comprehension. Misunderstanding is always possible because those involved in the speech act interpret statements differently. This misunderstanding is initially more likely with culturally divergent speakers than with speakers of one culture, whereby the model of multi-collectivity here shows that other factors can also force a misunderstanding to occur. Everyone has their own set of linguistic tools. According to Weigand (2009a: 309) the relationship between verbal and non-verbal language use and the respective culturally shaped background plays a central role in any dialogue analysis. Furthermore, she argues that one can only correctly analyse one's own language if one uses other languages and cultures as a basis for comparison (cf. Weigand 2010: 5). The differences are based on knowledge and experience. Every human being has his or her very specific cognitive abilities, his or her very own emotions and individual preferences. People perceive the world, at least to some extent, in their very own way. So, according to Weigand (2009a: 309), it is not the individual situation that is multicultural, but always the individual players in a conversation who carry their own, differently shaped culture within themselves. Cultural values influence perception. Whenever people communicate with each other, they carry their own view of the world within them. In intercultural communication situations, the individual worldviews can be very far apart. Weigand (2009a: 251) speaks of the 'cultural unity of the Action Game'. In Grein (2018: 18), I illustrate the Dialogical Action Game as follows:

\author{
individual imprint \\ cultural imprint \\ specific cognition \& perception \\ emotions \\ principles of use of language
}

individual imprint

cultural imprint

specific cognition \& perception

emotions

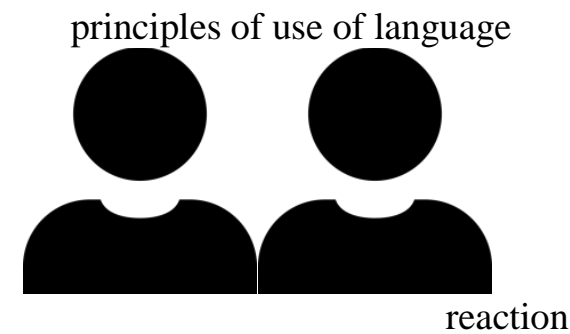

responding to this interest

verbal, non-verbal (such as action), para-verbal

verbal, non-verbal (such as action), para-verbal

Figure 1: Basis of understanding (cf. Grein 2007a: 20)

Whenever people communicate with each other, people meet with their very specific individual character, their very specific cognition and perception, their respective emotions and their linguistic skills. Cultural imprinting is therefore only one factor that influences these linguistic principles and the perception of the situation. Amiri (2018) illustrates the culture-specific differences using numerous concrete examples, of which I would like to use one as an illustration (Amiri 2018: 48): Situation: requesting an appointment Participants: professor and student

\section{Iran:}

A: Salāmjenābe Doktor B. Ozrmixām, mozāhemetunšodam. Mitunamazhozuretun ye soālbeporsam?

A: Hello, Your Excellency Doctor B. Excuse me, I'm disturbing you. May I ask a question in your presence?

B: Bale, xahešmikonam. Befarmaeeddāxellotfan.

B: Yes, please. Please enter.

A: Bebaxšidostād, mixāstambebinam key vaqtdarid vase pāyānnāmeberesamxedmatetun?

A: Excuse me, master, I wanted to know when you would have time for me to be in your service for my master's thesis?

B: Fardāsāat 4 biayddaftare man.

B: Come to my office tomorrow at $4.00 \mathrm{pm}$.

A transferral, i.e. a transfer in the sense of a direct translation, of this Dialogical Action Game into English is not very authentic. Culture shapes the individual and thus also the Dialogical Action Game through internalised habits 
and preferences, which are mostly long-lasting. However, due to growing globalisation, there have been changes, especially in terms of values. Actions, opinions and linguistic expressions are perceived specific to culture. A training of intercultural competence requires the analysis of such authentic sequences in order to minimise misunderstanding. Learners of a foreign language must be confronted with exactly these Dialogical Action Games in order to be sensitised to culturally specific differences. Weigand (2009b: no p.) argues:

In learning a foreign language, students will become aware of the fact that there are, on the one hand, specific types of utterances which, as types, seem to be universal: the direct, indirect and idiomatic utterance. On the other hand, they have to learn language-specific features, i.e. differences between their mother language and the foreign language. This first concrete dialogue Action Game has made it clear that language and language use are certainly both individual and culturally specific. Rathje's Multi-Collectivity approach (2014) focuses on the individuality of people and also makes it clear that culture is only one facet of humans and, thus, human communication.

\subsection{Multi-Collectivity}

The concept of Multi-Collectivity by Rathje (2006, 2014; based on Hansen 2011 [Original 2000]) also emerged during the discussion on the contentious concept of culture and is primarily directed against the often very stereotypical representations in intercultural training. Rathje (2014: 39) writes:

In so-called intercultural trainings, we learn that the Chinese absorb collectivism from their early childhood, the French communicate elegantly and that modesty is extremely important to Swedes. Initially, this seems plausible to us, since the external influence of the social environment on the individual cannot be denied. At the same time, however, we are also aware that this influence cannot be exclusive and predictable. The direct transfer of certain collective characteristics to individual people therefore makes us morally and intellectually uncomfortable.

The aim of her approach is to make it evident that every human being belongs to a large number of collectives or as she describes:

The central idea of Multi-Collectivity is the recognition that the multiple and diverse affiliations of the individual form a constitutive element of human existence. In contrast to an outdated understanding of culture, which primarily assigned individuals to a single collective context, numerous collective memberships are no longer regarded as an exception or disruptive factor of a theory, but form the basis for a changed understanding of the individual and his/her individuality (Rathje 2014: 42).

Within the framework of Multi-Collectivity, the focus is not on diversity, i.e. the differences between individual people, but on their similarities through their individual multiple affiliations. It is no longer intercultural competence that needs to be trained, but rather inter-collective competence, in which case culture is merely one facet of the 'collective'. In order to elucidate these multiple affiliations, I would like to take myself as an example. For one, I am part of the 'German' collective, but have numerous other affiliations:

German

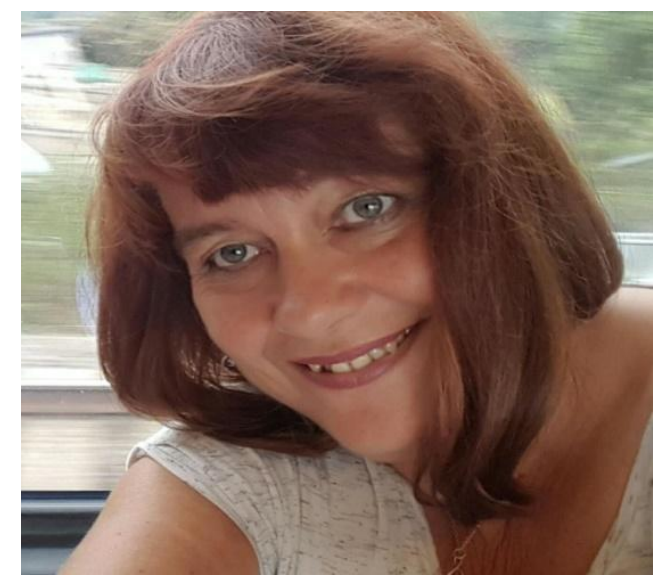

but also:

Doctoral advisor

Japan enthusiast

Crime-novel reader

Aperol-Spritz drinker

Cook

Concert visitor

Facebook user

Coffee lover

Blog writer

Lover of palm trees, the sun and sea

Smoker

Seminar traveller

Author

etc.

Figure 2: My collectives

In contact with people from other cultures, the focus doesn't have to be on the differences butcould be on the similarities or connecting elements: 


\section{German

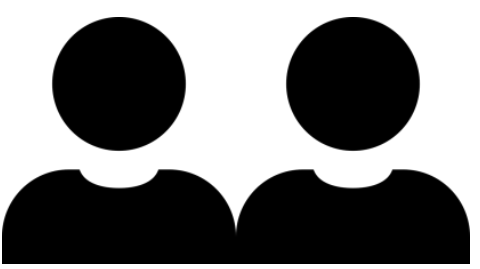 \\ Japanese \\ student \\ English as the first foreign language \\ SSocialised as female \\ movie enthusiast \\ city dweller \\ part of the middle class \\ same age \\ prefers Spain as a holiday destination \\ etc.}

Figure 3: Multi-Collectivity: connecting elements

In contrast, you can compare two people of one culture:

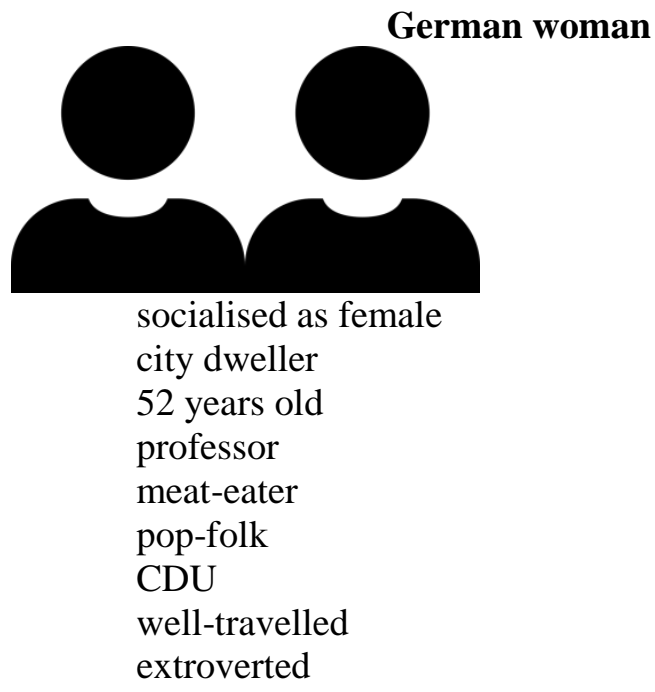

\section{German man}

socialised as male

country bumpkin

17 years old

student

vegan

Hip Hop

Greens

has never left the region

introverted

Figure 4: Multi-collectivity separating elements

The juxtaposition makes it clear that the same cultural imprint is no guarantee for communication to be successful. Culture is merely an element, one collective that either connects people or emphasises differences.

\subsection{Connecting Dialogical Action Game and Multi-Collectivity}

The two models can now be combined to develop intercultural competence. I think it is sensible to start with concrete dialogues, i.e. authentic Dialogic Action Games. Mono-cultural dialogues,such as the above-cited Persian dialogue,reveal that dialogues between different groups take a different course because they belong to different collectives (e.g. age group, social class, different professions, etc.). It is then also possible to analyse the similarities between different cultures. Nevertheless, it becomes evident that cultural differences cannot be denied. Let us compare two examples from Amiri (2018: 51f.) again:

Situation: greeting on the street

Participants: two young girls 


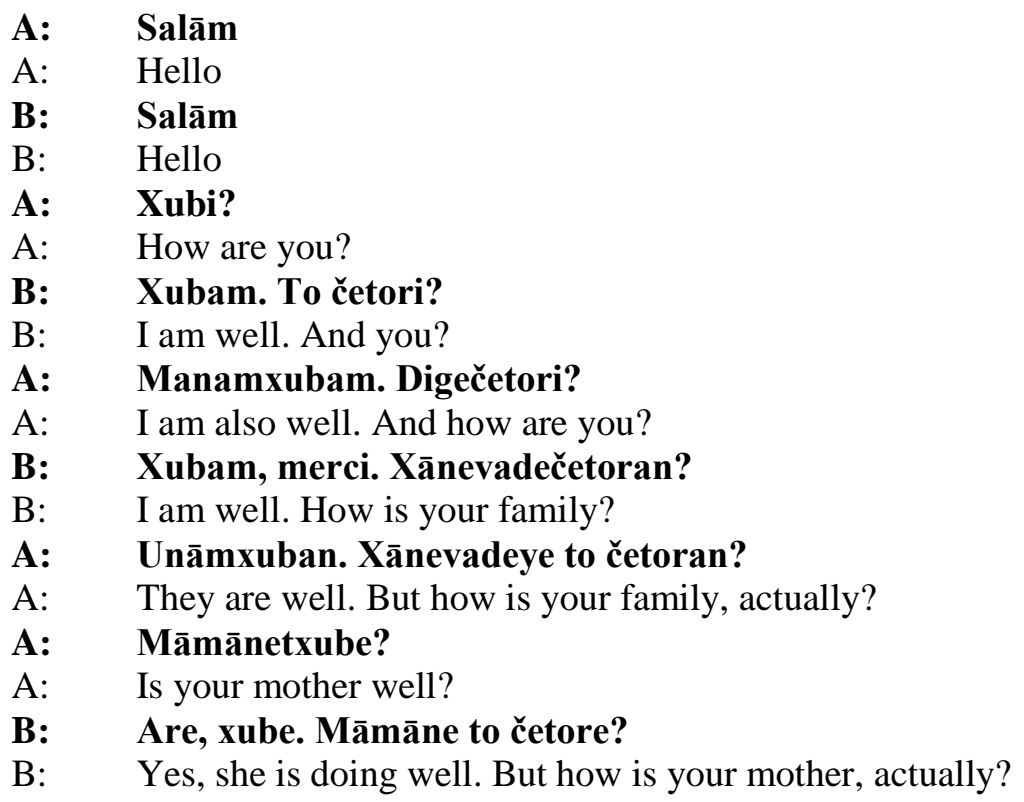

The greeting sequence between two young women in no way corresponds to the greeting sequence that you would find in the same constellation in Germany. Amiri (2018) outlines in detail that eye and body contact are also very different and also focus on the deviations in the area of the non-verbal between different genders. Based on concrete dialogues, differences and similarities can be worked out.As a last example from Amiri (2018: 59), I would like to include the Dialogical Action Game in matters of compliments and compliment response. In Iran, compliments are mainly expressed by women to women. Here, again, two young women are involved:
A: Vay! Čeqadkaf̌̃aye not qašanqan!
A: Wow! Your new shoes are really nice.
B: $\quad$ Merciazizam. Češmātqašanqmibinan. Qābelinadāre.
B: Thank you, love. Your eyes are beautiful. Take good care of them!
A: Sāhebešqābeldāre. Be pāye to qašangan.
A: You (as a shoe owner) are also very valuable. But they only look great on you.
B: Be qašangiekafšāye to nemiresan.
B: But your shoes look even nicer.
A: Merciazizam, lotfdāri.
A: Thank you, love. That is really kind of you to say.

In German, we would not return the complement to the person, nor would we have to offer a reciprocal compliment. This example makes it quite clear that an analysis using minimal yet authentic Action Games proves to be productive. However, reality also shows that the author, Anita Amiri, has more in common with her German friends, who she is close to.

\section{Summary}

Intercultural competence, understood as a basic competence to act, requires a sensitization for cultural differences without neglecting the similarities of the speakers. Negating culture-specific differences is of little help and, if one compares the three Action Games shown, is simply meaningless. If one considers the Multi-Collectivity approach, it becomes clear that there are more connecting elements between people (also from different cultures). The approach of a minimal Action Game offers a way to approach culturally shaped differences. Explanations for existing, culture-specific differences are then provided by the various dimensional approaches, which are not outlined here.

numerous individual collectives cultural imprint numerous individual collectives

cultural imprint 


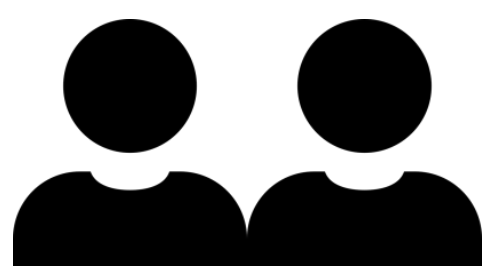

action

communicative interest reaction

response to this interest

verbal, non-verbal (such as action), para-verbal

verbal, non-verbal (such as action), para-verba

Figure 5: Multi-Collectivity in the Dialogical Action Game

Sensitization for the connecting elements, i.e. the different collectives one belongs to, as well as sensitization for culturally specific differences through concrete minimal Action Games allows you, in my opinion, to promote intercultural competence. The backgrounds for the divergent Action Games can then be analysed with the help of the dimensional approaches if required.

\section{Bibliography}

Amiri, Anita (2018): Authentizität und Wertkonflikte. DaF Lehrwerkefür den Iran. BeiträgezurDidaktik. Herzogenrath: Shaker.

Bergmann, Britta \& Bergmann, Nils (2005): InterkulturelleManagementkompetenz. Anforderung und Ausbildung. Heidelberg: PhysikaVerlag.

Bolten, Jürgen (2006): InterkulturelleKompetenz. 3. Edition. Erfurt: LandeszentralefürpolitischeBildung.

Chen, Guo-Ming \&Starosta, William G. (1998): Foundations of Intercultural Communication. Boston: Allyn\& Bacon.

Damasio, Antonio (2000): Ichfühle, also bin ich. Die Entschlüsselung des Bewusstseins. Munich: List.

Fritz, Wolfgang, Möllenberg, Anja \& Chen, Guo-Ming (2002): Measuring intercultural sensitivity in different cultural contexts, in: Intercultural Communication Studies, 11 Jg., 2, p. 165-176.

Gertsen, Martine Cardel (1990): Intercultural competence and expatriates. In: The International Journal of Human Resource Management, Vol 1, No.3, 341-362.

Grein, Marion (2017a): Das Mixed Game Model in der interkulturellenForschung. In: Grein, Marion \& Ersch, Maria (eds.) NeuemethodischeAnsätzeim DaF-Unterricht. Vol. 3. Mainz: SalonlöweVerlag. Edition Wissenschaft. 23-37.

Grein, Marion (2017b): How culture affects language and dialogue. In: The Routledge Handbook of Language and Dialogue, New York \& London: Routledge. 347-366.

Grein, Marion (2018): Foreign language teaching - Integrationism vs. MGM. Language and Dialogue. Special issue. Integrating Dialogue, ed. by R. Saftoiu and A. Pablé. 18:1. Amsterdam: John Benjamins. 5-20.

Hall, Edward T. (1966): The Hidden Dimension. New York: Garden City.

Hall, Edward T. (1976): Beyond Culture. New York: Garden City.

Hall, Edward T. (1983): The Dance of Life: The other dimension of time. New York: Anchor Books.

Hansen, Klaus P. (2011): Kultur und Kulturwissenschaft. 4. edition Tübingen: A. Franckeutb.

Hofstede, Geert (2017): LokalesDenken, globalesHandeln: InterkulturelleZusammenarbeit und globales Management. 6. edition Munich: Beck.

Müller, Stefan \&Gelbrich, Katja (2004): Interkulturelles Marketing. Munich: Vahlen.

Rathje, Stefanie (2006): InterkulturelleKompetenz - Zustand und ZukunfteinesumstrittenenKonzepts. ZeitschriftfürinterkulturellenFremdsprachenunterricht, H.2, 2006.

Rathje, Stefanie (2014): Multikollektivität. Schlüsselbegriff der modernenKulturwissenschaften. In: Wolting, Stephan (Hrsg.), Kultur und Kollektiv. Festschrift für Klaus P. Hansen. Berlin: wvb. 39-59.

Ruben, Brendt D. (1976): Assessing communication competency for intercultural adaptation, in: Group \& Organization Studies, 1. Jg., 3, p. 334-354.

Thomas, Alexander (2003): InterkulturelleKompetenz - Grundlagen, Probleme und Konzepte. Erwägen, Wissen, Ethik Jg. 14, H.1, $137-150$

Triandis, Harry Charalambos (1977): Interpersonal behavior. Monterey, CA: Brooks/ Cole Pub. Co.

Vanderheiden, Elisabeth \& Mayer, Claude-Hélèn (2014): HandbuchInterkulturelleÖffnung. Grundlagen, Best Practice, Tools. Göttingen: Vandenhoeck\&Ruprecht.

Weigand, Edda (2009a): Language as Dialogue. Amsterdam \& Philadelphia: John Benjamins.

Weigand, Edda (2009b): Teaching a Foreign Language. A Tentative Enterprise. In: Toolan, Michael (ed.) Language Teaching. Integrational Linguistic Approaches. New York: Routledge (Vital Book File) 120-139.

Weigand, Edda (2010): Dialogue. The Mixed Game. Amsterdam \& Philadelphia: John Benjamins.

Welsch, Wolfgang (1994): 'Transkulturalität - die veränderteVerfassungheutigerKulturen. EinDiskursmit Johann Gottfried Herder.' in: VIA REGIA - BlätterfürinternationalekulturelleKommunikation Heft 20/ 1994, published by the EuropäischeKulturund Informationszentrum in Thüringen.

Zülch, Martin (2004): 'McWorld'oder'Multikulti'? InterkulturelleKompetenzimZeitalter der Globalisierung. In: GüntherVedder (ed.) Diversity Management und Interkulturalität. Munich/ Mering, 3-26. 